\title{
In vitro effect of low intensity laser on the cytotoxicity produced by substances released by bleaching gel
}

\section{Caroline Maria Gomes Dantas ${ }^{(a)}$ Carolina Lapaz Vivan (a) Leila Soares Ferreira ${ }^{\text {(b) }}$ Patrícia Moreira de Freitas ${ }^{(c)}$ Márcia Martins Marques(c)}

(a) School of Dentistry, Universidade de São Paulo, São Paulo, SP, Brazil.

(b) Graduate Program in Restorative Dentistry, School of Dentistry, Universidade de São Paulo, São Paulo, SP, Brazil.

(c) Department of Restorative Dentistry, School of Dentistry, Universidade de São Paulo, São Paulo, SP, Brazil

\section{Corresponding author:}

Caroline Maria Gomes Dantas

Rua Pio Xl, 1644

São Paulo - SP - Brazil

CEP: 05468-140

Email: carolinedantas@usp.br

Received for publication on Aug 17, 2010 Accepted for publication on Oct 06, 2010

\begin{abstract}
This in vitro study aimed to analyze the effect of different parameters of phototherapy with low intensity laser on the viability of human dental pulp fibroblasts under the effect of substances released by bleaching gel. Cells were seeded into 96 wells plates $\left(1 \times 10^{3}\right.$ cells/well) and placed in contact with culture medium conditioned by a $35 \%$ hydrogen peroxide bleaching gel for 40 minutes, simulating the clinical condition of the in-office bleaching treatment. Cells cultured in ideal growth conditions served as positive control group (PC), and the cells grown in conditioned medium and non-irradiated served as negative control group (NC). Cells grown in conditioned medium were submitted to a single irradiation with a diode laser $\left(40 \mathrm{~mW}, 0.04 \mathrm{~cm}^{2}\right)$ emitting at visible red (660 nm; RL) or near infrared (780 nm; NIR) using punctual technique, in contact mode and energy densities of 4,6 or $10 \mathrm{~J} / \mathrm{cm}^{2}$. The cell viability was analyzed through the MTT reduction assay immediately and 24 hours after the irradiation. The data was compared by ANOVA followed by the Tukey's test $(\mathrm{p} \leq 0.05)$. The cell viability increased significantly in 24 hours within each group. The PC presented cell viability significantly higher than NC in both experimental times. Only the NIR/10 J/ $\mathrm{cm}^{2}$ group presented cell viability similar to that of PC in 24 hours. The phototherapy with low intensity laser in defined parameters is able to compensate the cytotoxic effects of substances released by $35 \%$ hydrogen peroxide bleaching gel.
\end{abstract}

Descriptors: Tooth Bleaching; Fibroblasts; Phototherapy; Lasers

\section{Introduction}

The increasing demand for aesthetic treatments led the tooth bleaching to be one of the most required dental procedures. However, this procedure can cause side effects such as external root resorption, oral irritation, alteration of enamel surface and, especially, post-treatment tooth sensitivity. ${ }^{1}$ The etiology of this sensitivity has not been fully elucidated and, among other factors, may be associated with hydrogen peroxide diffusion through mineralized dental structures. ${ }^{2-4}$ When it reaches the pulp chamber, it can trigger reversible inflammation. ${ }^{5,6}$

Tooth bleaching agents, carbamide peroxide or hydrogen peroxide, undergo ionization and decay, producing free radicals. Free radicals are highly unstable and exhibit remarkable ability to react with other organic substances ${ }^{7}$ and may even cause damage to cellular DNA. ${ }^{78}$ In fact, 
damage to odontoblasts in vivo and fibroblasts in vitro has been reported after contact with bleaching agents. $^{9-11}$ Therefore, bleaching agents can release substances that lead to alteration of cellular metabolism and/or inflammation in dental pulp.

Phototherapy with low intensity laser is used in various areas of biological sciences to promote tissue regeneration of injured tissues. This therapy results in analgesic, antiinflammatory and biomodulatory effects. ${ }^{12-14}$ The laser light within the red visible and near infrared wavelengths corresponds to the energy absorption spectrum of the respiratory chain components, increasing the cellular metabolism under stress conditions. ${ }^{12,15-18}$

The photon energy is converted into chemical energy within the cell, forming ATP, ${ }^{5,16}$ which may lead to increased intracellular $\mathrm{Ca}^{+2} \cdot{ }^{18,19}$ This will ultimately stimulate duplication of DNA, ${ }^{20,21}$ protein synthesis increase, ${ }^{13}$ induction of the action of enzymes that control the oxidative stress, ${ }^{12,17,22}$ modulation of fibroblast growth factors production, which in turn will stimulate cell proliferation. . $^{15,17,21,23-25}$

Based on the above, phototherapy with low intensity laser would be of importance for restoring the integrity of dental pulp after bleaching, especially for postoperative symptoms control. Thus, phototherapy with low intensity laser could be used as additional clinical procedure for tooth bleaching. However, it is imperative to test this therapy on cells and tissues sensitized by substances released by the bleaching agent capable of reaching the dental pulp. Therefore, this study aimed to evaluate the degree of cytotoxicity of substances released by a bleaching agent on human fibroblasts. Additionally, the ability of the phototherapy with low intensity laser in different parameters for compensating the cytotoxic effects of these substances will be assessed.

\section{Material and Methods Cell culture}

This study was previously approved by the Universidade de São Paulo Ethical Committee, 89/2008 (FR 18810). Dental pulp fibroblasts (FP5 cell lineage) were grown in DME-HAM's F12 medium (Sigma Aldrich, St. Louis, MO, USA) supplemented by $20 \%$ fetal bovine serum (Invitrogen Carlsbad,
California, EUA) in incubator at $37^{\circ} \mathrm{C}$ in humid atmosphere containing $5 \% \mathrm{CO}_{2}$ and $95 \%$ air. The cells grown in culture flasks were harvested and platted into 96 wells culture plates.

\section{Conditioned medium}

The culture medium conditioned by the bleaching agent was obtained as described by Cavalcanti et al. ${ }^{26}$ For obtaining the conditioned medium, $0.2 \mathrm{~g}$ of $35 \% \mathrm{H}_{2} \mathrm{O}_{2}$ (Ultradent, South Jordan, UT, USA) per $1 \mathrm{~mL}$ of culture medium was used. The conditioning time was 30 minutes, and immediately after conditioning the conditioned medium diluted to $10^{-3}$ was applied to the cell cultures.

\section{Experiments}

For the experiments the fibroblasts were seeded in 6 plates of 96 wells $\left(1 \times 10^{3}\right.$ cell/well). These wells were distributed in the plates with the maximum possible distance between each other in order to avoid interferences amongst the different experimental groups. Control cultures were plated in culture plates not subjected to irradiation.

Twenty-four hours after the cell seeding the culture medium was exchanged by the conditioned medium, except for the control group that received fresh culture medium. The conditioned medium was remained in contact with the cells for 40 minutes, in order to simulate the bleaching procedure time of a clinical session. Then, the media of all wells were replaced by fresh culture medium and the cell cultures were or not (control) irradiated.

The cell viability of all groups was measured immediately ( 0 hour) and 24 hours later. This analysis was based on cell mitochondrial activity measured by the MTT (Invitrogen) based cytotoxicity assay. ${ }^{27}$ Immediately after the end of the assay procedures the absorbance was read in a microplate reader (Biotrak II, Biochrom Ltd., Eugendorf, Austria) using a $562 \mathrm{~nm}$ filter. According to Freshney, ${ }^{28}$ this assay determines indirectly the cell viability. Thus, the absorbance data of the control group grown in ideal cell culture conditions indicates the maximum cell number in one well. The comparison of this data with those of the other experimental groups will indirectly indicate the number of viable cells in the 
experimental wells.

\section{Statistical Analysis}

The optical density data, corresponding to the cell viability, obtained in four replicates are presented as mean \pm standard error of the mean (SEM). The data were compared by ANOVA test followed by the Tukey's test. The level of significance was $5 \%$ $(\mathrm{p} \leq 0.05)$.

\section{Experimental groups}

The experimental groups were, as follows:

- Positive Control (PC): Cells grown in fresh medium and non-irradiated.

- Cells grown in conditioned medium:

- Negative Control (NC): non-irradiated

- RL1: irradiated: $660 \mathrm{~nm}, 4 \mathrm{~J} / \mathrm{cm}^{2}$

- RL2: irradiated: $660 \mathrm{~nm}, 6 \mathrm{~J} / \mathrm{cm}^{2}$

- RL3: irradiated: $660 \mathrm{~nm}, 10 \mathrm{~J} / \mathrm{cm}^{2}$

- NIR1: irradiated: $780 \mathrm{~nm}, 4 \mathrm{~J} / \mathrm{cm}^{2}$

- NIR2: irradiated: $780 \mathrm{~nm}, 6 \mathrm{~J} / \mathrm{cm}^{2}$

- NIR3: irradiated: $780 \mathrm{~nm}, 10 \mathrm{~J} / \mathrm{cm}^{2}$

\section{Phototherapy with low intensity laser}

The phototherapy with low intensity laser was carried out with a diode laser (Twin Laser, MMOptics, São Carlos, SP, Brazil) which emits irradiation in two wavelengths, as follows: $660 \mathrm{~nm}$ (AlGaInP) for the RL groups and $780 \mathrm{~nm}$ (GaAlAs) for the NIR groups. The output power was $40 \mathrm{~mW}$, spot size of $0.04 \mathrm{~cm}^{2}$, in contact using a punctual and continuous mode. The information of dosimetry is presented in Table 1.

The LaserCheck powermeter (Coherent, Inc., Santa Clara, CA) was used to verify the output pow- er of the laser equipment. The control groups were treated under identical conditions except that the laser equipment was kept off.

\section{Results}

The cell viability in all groups increased significantly in 24 hours $(\mathrm{p}<0.01)$. The PC presented cell viability significantly higher than NC in both experimental times $(\mathrm{p}<0.01)$.

In the first evaluation period (zero hour), the groups irradiated with the visible red laser presented cell viability similar to that of the NC, except for the RL3 group that reached cell viability values similar to those of PC. In 24 hours, all groups irradiated with red visible laser presented cell viability significantly higher than that of $\mathrm{NC}(\mathrm{p}<0.01)$; however they did not reach the values of PC.

Amongst the groups irradiated with near infrared laser, the NIR1 presented cell viability values similar to those of NC in both experimental times. The groups NIR2 and NIR3 presented cell viabilities similar to those of NC in the time 0 (zero), and values significantly higher in 24 hours $(\mathrm{p}<0.01)$. Only the NIR 3 group presented in 24 h cell viability values similar to those of PC.

The optical density values observed in the wells of all experimental groups in both experimental times are presented in Table 2, and illustrated in Figure 1.

\section{Discussion}

The mechanisms of tooth bleaching involve the extracellular matrix degradation and oxidation of chromophores located in dentin and enamel. However, peroxide can lead to undesirable effects on the

\begin{tabular}{|c|c|c|c|c|c|c|}
\hline \multirow{8}{*}{$\begin{array}{r}\text { Table } 1 \text { - Dosimetry } \\
\text { parameters used in } \\
\text { the study. }\end{array}$} & \multirow{2}{*}{$\begin{array}{c}\text { Groups } \\
\text { PC and NC }\end{array}$} & $\begin{array}{l}\text { Wavelength } \\
(\mathrm{nm})\end{array}$ & $\begin{array}{c}\text { Fluency }\left(\mathrm{J} / \mathrm{cm}^{2}\right) / \\
\text { Energy }(\mathrm{J})\end{array}$ & $\begin{array}{l}\text { Power } \\
(\mathrm{mW})\end{array}$ & Time (s) & $\begin{array}{l}\text { Irradiance } \\
(\mathrm{mW} / \mathrm{s})\end{array}$ \\
\hline & & - & - & - & - & - \\
\hline & RL 1 & 660 & $4 / 0.16$ & 40 & 4 & 10.0 \\
\hline & RL2 & 660 & $6 / 0.24$ & 40 & 6 & 6.6 \\
\hline & RL3 & 660 & $10 / 0.40$ & 40 & 10 & 4.0 \\
\hline & NIR 1 & 780 & $4 / 0.16$ & 40 & 4 & 10.0 \\
\hline & NIR2 & 780 & $6 / 0.24$ & 40 & 6 & 6.6 \\
\hline & NIR3 & 780 & $10 / 0.40$ & 40 & 10 & 4.0 \\
\hline
\end{tabular}


Table 2 - Cell viability of the different experimental groups in function of experimental times in hours (mean \pm standard error of the optical densities)

\begin{tabular}{c|c|c|c|c|c|c|c|c}
\hline Time (hours) & PC & NC & RL1 & RL2 & RL3 & NIR1 & NIR2 & NIR3 \\
\hline 0 & $0.56 \pm 0.04$ & $0.22 \pm 0.03$ & $0.36 \pm 0.03$ & $0.28 \pm 0.02$ & $0.44 \pm 0.02$ & $0.19 \pm 0.02$ & $0.23 \pm 0.04$ & $0.25 \pm 0.01$ \\
\hline 24 & $1.05 \pm 0.07$ & $0.60 \pm 0.04$ & $0.83 \pm 0.05$ & $0.76 \pm 0.05$ & $0.78 \pm 0.05$ & $0.69 \pm 0.02$ & $0.80 \pm 0.01$ & $0.96 \pm 0.03$ \\
\hline
\end{tabular}

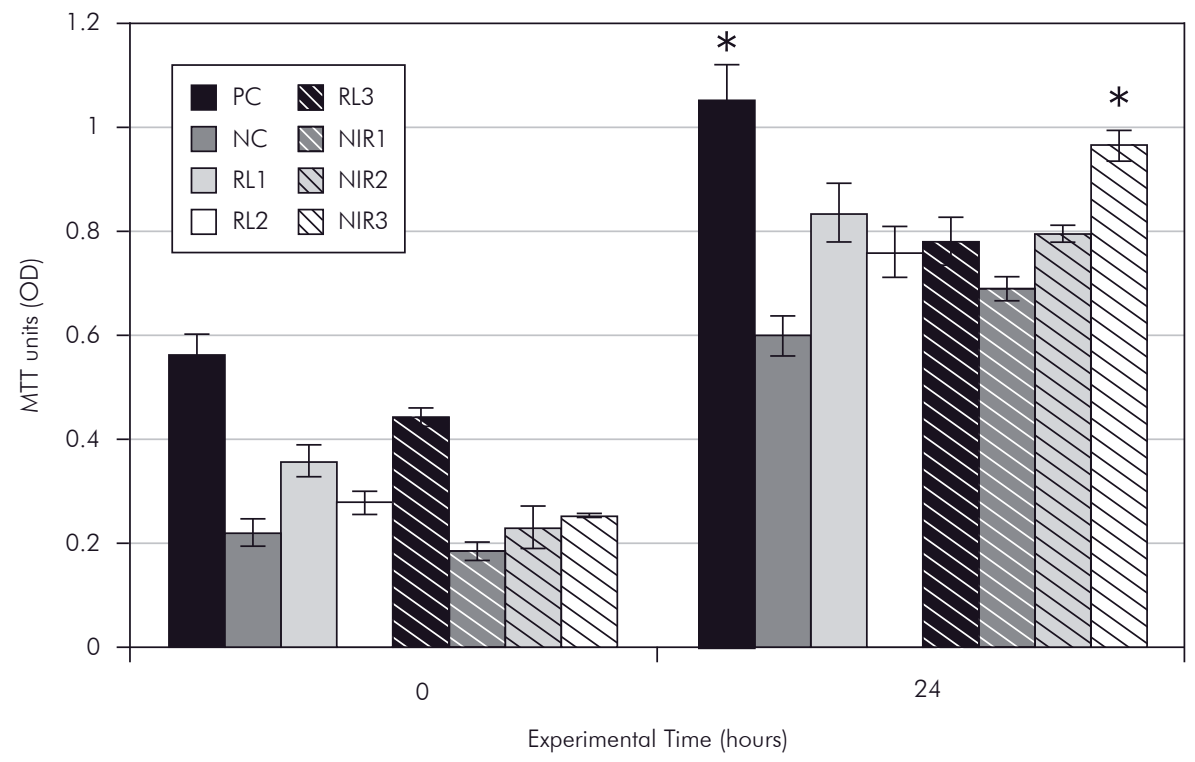

Figure 1 - Graphic representation of the mean cell viability (optical densities) in function of the experimental time (hours). PC: Positive Control; NC: Negative Control: RL: Red Laser, NIR: Near InfraRed laser. [ ${ }^{*}$ Similar cell viabilities ( $\left.p>0.05\right)$. Bar means standard error of the mean.]

tooth and other oral tissues. ${ }^{29} \mathrm{With}$ the aim of testing a therapy that could contribute to control these undesirable effects, this study has used laser phototherapy with low intensity laser. Several parameters were tested and the viability of cultured human pulp fibroblasts that had been sensitized by substances released by bleaching gel prior to irradiation was measured. The results showed that these substances are cytotoxic in vitro. Moreover, the phototherapy with low intensity laser using specific parameters was able to compensate the cytotoxic effects of the gel. This could be resultant of either partial or even the total cell viability maintenance, or by stimulating the proliferation of surviving cells.

The literature reports controversies about the effects of bleaching agents on dental structures. Thus, the in vitro results - although they cannot be directly extrapolated to clinical practice - can bring data to a better understanding about the effects of substances released by bleaching gel on pulp cells, as well as the influence of the phototherapy with low intensity laser in this clinical situation. Although this study had employed in vitro techniques, the parameters of this study were similar to those applied in the in-office bleaching procedure. In this respect, medium conditioned by the gel was chosen to be used. This medium contains substances released by the gel, which would be those substances that effectively penetrate the enamel and dentin and that could lead to pulpal response. Another clinical parameter used in the methodology was related to the time of cell exposure to the conditioned medium, which was 40 minutes, in an attempt to observe the same time that the pulp is subjected to the action of the gel in vivo in the in-office bleaching session. In the methodology it was also considered that phototherapy with low intensity laser is unable to induce cell growth above that characteristic of cell culture grown in its ideal condition of cultivation, as demonstrated by Almeida-Lopes et al. ${ }^{30}$ For this reason, in this study a control group grown in ideal conditions of cultivation and irradiated was not considered, since the viability of this group would be similar to that of the non irradiated control group. 
The toxic effect of bleaching agents is well documented. In fact, the findings of the current study showed that cultured cells that came into contact with the conditioned medium and did not receive irradiation had significantly lower viability than cells grown under ideal conditions of cultivation. Thus, cell death caused by the bleaching agents could be partially responsible for the post-bleaching symptoms.

The bleaching agents probably lead to cell destruction in the pulp due to the inactivation of enzymes and disruption of normal cells, but the pulp changes are described as transient and clinically reversible. ${ }^{1,6}$ The present study also showed a cytotoxic effect of the substances released by the bleaching gel, that was transient once the laser irradiation was able to offset this effect. In fact, different levels of cellular response to substances released by the bleaching agent were observed. The most striking response was the significantly decreased cell viability in the negative control group. However, when cells exposed to conditioned medium were irradiated with near infrared laser and $0.4 \mathrm{~J}$, this effect was fully offset and the viability reached the positive control values within 24 hours.

It is described in the literature that hydrogen peroxide would cause an increase in the oxidative cell stress. $^{7-9}$ The laser light emitting at the visible red spectrum stimulates the respiratory chain in cells under stress, leading to alterations in electron transport by mitochondria. ${ }^{16,17,19,22,25}$ Then, besides the increase in ATP synthesis, there is signaling to the nucleus stimulating the production of antioxidant enzymes, proteins that stabilize cellular function and proliferation. ${ }^{20,21,16,17,22}$

On the other hand, irradiation in the infrared spectrum stimulates calcium channels of the cell membrane. ${ }^{18}$ The increase in intracellular $\mathrm{Ca}^{2+}$ gradient may explain the increased cell viability observed in the treated group compared to control subjected to the same stress conditions, where this stimulation facilitates the occurrence of cell proliferation.

In conclusion, it is possible to consider that the phototherapy with low intensity laser using specific parameters described in the current study was able to compensate the cytotoxic effects released by the bleaching gel. It is quite likely that two or more of the action mechanisms of phototherapy should have occurred simultaneously in irradiated cultures and were responsible for the observed biological response. The increase of cellular activity by increasing metabolism or proliferation in the irradiated groups can be considered as a beneficial effect of therapy, even if these results were obtained using in vitro systems and cannot be transported directly to the in vivo systems.

Based on the results of this study, the use of phototherapy with low intensity laser in in vivo studies would be of relevance in order to extend the observations about the effects of this therapy in the control and prevention of undesirable side effects of tooth bleaching. From the parameters used here, which have shown effectiveness in offsetting the cytotoxicity of substances released by bleaching gel, one could study the pulpal response of teeth of animals subjected to tooth bleaching followed by phototherapy with low intensity laser. New parameters could also be tested to determine efficient protocols for the application of this therapy that has been used in dental practice with important effects on several other clinical situations.

\section{Conclusion}

Based on the conditions of this study it was concluded that:

1. Substances released by the bleaching gel containing $35 \%$ hydrogen peroxide are cytotoxic to human cultured fibroblasts.

2. The phototherapy with low intensity laser emitting in the visible red $(660 \mathrm{~nm})$ in the parameters used in this study was able to compensate the cytotoxic effects of substances released by the bleaching gel containing 35\% hydrogen peroxide.

3. The phototherapy with low intensity laser emitting in the near infrared $(780 \mathrm{~nm})$ in the parameters used in this study was able to compensate the cytotoxic effects of substances released by the bleaching gel containing 35\% hydrogen peroxide. 


\section{Acknowledgements}

This study was supported by the State of São Paulo Research Foundation (FAPESP grant \#2008/02611-9 and \#2008/05241-8) and the National Council of Scientific and Technological De-

\section{References}

1. Dahl JE, Pallesen U. Tooth bleaching--a critical review of the biological aspects. Crit Rev Oral Biol Med. 2003 Jul;14(4):292304.

2. Benetti AR, Valera MC, Mancini MN, Miranda CB, Balducci I. In vitro penetration of bleaching agents into the pulp chamber. Int Endod J. 2004 Feb;37(2):120-4.

3. Ruse ND, Smith DC, Torneck CD, Titley KC. Preliminary surface analysis of etched, bleached, and normal bovine enamel. J Dent Res. 1990 Sep;69(9):1610-3.

4. Bowles WH, Ugwuneri Z. Pulp chamber penetration by hydrogen peroxide following vital bleaching procedures. J Endod. 1987 Aug;13(8):375-7.

5. Robertson WD, Melfi RC. Pulpal response to vital bleaching procedures. J Endod. 1980 Jul;6(7):645-9.

6. Seale NS, Wilson CFG. Pulpal response to bleaching of teeth in dogs. Pediatr Dent 1985 Feb;7(3):209-14.

7. Li Y. Biological properties of peroxide-containing tooth whiteners. Food Chem Toxicol. 1996;34(9):887-904

8. Ribeiro DA, Marques MEA, Salvadori DMF. Study of DNA damage induced by dental bleaching agents in vitro. Braz Oral Res. 2006 Jan/Mar;20(1):47-51.

9. Koulaouzidou EA, Papazisis KT, Economides N, KaranikaKouma A, Kortsaris AH. Cytotoxicity of 2 bleaching agents: an in vitro study. Balk J Stom. 2008 Jul;12(2):89-92.

10. Dias Ribeiro AP, Sacono NT, Lessa FC, Nogueira I, Coldebella CR, Hebling J, et al. Cytotoxic effect of a $35 \%$ hydrogen peroxide bleaching gel on odontoblast-like MDPC-23 cells. Oral Surg Oral Med Oral Pathol Oral Radiol Endod. 2009 Sep;108(3):458-64.

11. Anderson DG, Chiego DJ, Glickman GN, Mccauley LK. A clinical assessment of the effects of $10 \%$ carbamide peroxide gel on human pulp tissue. J Endod. 1999 Apr;25(4):247-50.

12. Silveira PCL, Streck EL, Pinho RA. Evaluation of mitochondrial respiratory chain activity in wound healing by low-level laser therapy. J Photochem Photobiol B. 2007 Mar;86(3):279282.

13. Reddy GK. Photobiological basis and clinical role of lowintensity lasers in biology and medicine. J Clin Laser Med Surg. 2004 April;22(2):141-50.

14. Ladalardo TCCGP, Pinheiro A, Campos RAC, Brugnera Júnior A, Zanin F, Albernaz PLM, et al. Laser therapy in the treatment of dentine hypersensitivity. Braz Dent J. 2004 Apr;15(2):144-150. velopment (CNPq). The authors also thank the Special Laboratory of Laser in Dentistry (LELO) and the Laboratory of Basic Research from the Restorative Dentistry Department, School of Dentistry, University of São Paulo.

15. Hawkins D, Abrahamse H. Effect of multiple exposures of low-level laser therapy on the cellular responses of wounded human skin fibroblasts. Photomed Laser Surg. 2006 Dec;24(6):705-14.

16. Karu T. Photobiology of low-power laser effects. Helth Phys 1989 May; 56(5):691-704.

17. Jori G, Schindl L, Schindl A, Polo N. Novel approaches towards a detailed control of the mechanism and efficiency of photosensitized process in vivo. J Photochem Photobiol A. 1996 Dec;102(1):101-7

18. Lubart R, Friedmann H, Sinyakov M, Cohen N, Breibart H. Changes in calcium transport in mammalian sperm motichondria and plasma membranes caused by $780 \mathrm{~nm}$ irradiation. Lasers Surg Med. 1997 Dec;21(5):493-9.

19. Olson JE, Schimmerling W, Tobias CA. Laser action spectrum of reduced excitability in nerve cells. Brain Res. 1981 Jan;204(2):436-40.

20. Loevschall H, Arenholt-Bindslev D. Effect of low level diode lasers irradiation of human oral mucosa fibroblasts in vitro. Lasers Surg Med. 1994 Jan;14(4):347-354.

21. Yu HS, Chang KL, Yu CL, Chen JW, Chen GS. Low-energy helium-neon lasers irradiation stimulates interleukin-1 alpha and interleukin-8 release from cultured human keratinocytes. J Invest Dermatol. 1996 Oct;107(4):593-6.

22. Polo L, Presti F, Schindl L, Jori G, Bertoloni G. Role of gorund and excited singlet state oxygen in the red light-induced stimulation of Escherichia coli cell growth. Biochem Biophys Res Commum. 1999 Apr;257(3):753-8.

23. Moore P, Ridgway TD, Higbee RG, Howard EW, Lucroy MD. Effect of wavelength on low-intensity laser irradiation-stimulated cell proliferation in vitro. Lasers Surg Med. 2005 Jan;36(1):8-12.

24. Pereira AN, Eduardo C de P, Matson E, Marques MM. Effect of low-power laser irradiation on cell growth and procollagen synthesis of cultured fibroblasts. Lasers Surg Med. 2002 Oct;31(4):263-7.

25. Karu T. Primary and secondary mechanisms of action of visible to near-IR radiation on cells. J Photochem Photobiol B. 1999 Mar;49(1):1-7.

26. Cavalcanti BN, Rode SM, Marques MM. Cytotoxicity of substances leached or dissolved from pulp capping materials. Int Endod J. 2005 Aug;38(8):505-9. 
- In vitro effect of low intensity laser on the cytotoxicity produced by substances released by bleaching gel

27. Mossman T. Rapid colorimetric assay for cellular growth and survival: application to proliferation and cytotoxicity assays. J Immunol Methods. 1983 Jun;659(1-2):55-63.

28. Freshney RI. Cytotoxicity. In: Freshney RI. Biology of the cultured cell. Culture of animal cells: a manual of basic technique. 4 ed. New York: Willey; 2000. p. 332-345.
29. Goldberg M, Grootveld M, Lynch E. Undesirable and adverse effects of tooth-whitening products: a review. Clin Oral Investig. 2010 Nov;14(1):1-10.

30. Almeida-Lopes L, Rigau J, Zângaro RA, Guidugli-Neto J, Jaeger MM. Comparison of the low level laser therapy effects on cultured human gingival fibroblasts proliferation using different irradiance and same fluence. Lasers Surg Med. 2001 Jan;29(2):179-84. 